\title{
Mert Davies
}

A RAND Pioneer in

Earth Reconnaissance and

Planetary Mapping

from Spacecraft

Bruno W. Augenstein Bruce Murray 



\section{Mert Davies}

A RAND Pioneer in

Earth Reconnaissance and

Planetary Mapping

from Spacecraft

Bruno W. Augenstein Bruce Murray 
This publication was supported by RAND, using discretionary funds made possible by the generosity of RAND's donors and the fees earned on client-funded research.

The RAND Corporation is a nonprofit research organization providing objective analysis and effective solutions that address the challenges facing the public and private sectors around the world. RAND's publications do not necessarily reflect the opinions of its research clients and sponsors.

RAND $^{\circledR}$ is a registered trademark.

Cover design by Barbara Angell Caslon

(C) Copyright 2004 RAND Corporation

All rights reserved. No part of this book may be reproduced in any form by any electronic or mechanical means (including photocopying, recording, or information storage and retrieval) without permission in writing from RAND.

Published 2004 by the RAND Corporation 1700 Main Street, P.O. Box 2138, Santa Monica, CA 90407-2138

1200 South Hayes Street, Arlington, VA 22202-5050

201 North Craig Street, Suite 202, Pittsburgh, PA 15213-1516

RAND URL: http://www.rand.org/

To order RAND documents or to obtain additional information, contact

Distribution Services: Telephone: (310) 451-7002;

Fax: (310) 451-6915; Email: order@rand.org 


\section{Contents}

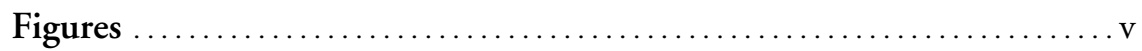

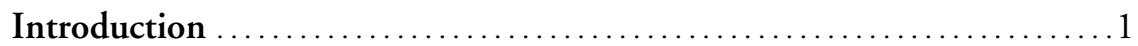

National Reconnaissance Career (1947-1970) ................... 2

Mert's Early Years at RAND .................................. 2

The Cold War Intensifies, the Needs for Intelligence Burgeon ........... 4

Davies Begins His Reconnaissance Satellite Studies .................... 9

National Intelligence Needs Lead to the CORONA Satellite Program ... 11

CORONA and RAND: Interactions and Issues................... 14

The Early Years of CORONA and Davies' Contemporary Career....... 19

Davies Begins to Switch Careers and Receives a Signal NRO Honor ..... 25

Planetary Exploration Emphasis (1965-2001) ................... 29

A Pioneering Vision for Deep Space Photographic Exploration ......... 29

Revolutionary Technical Steps Required to Advance from

Earth-Orbital to Planetary Spacecraft Imaging ....

The Innovations Introduced by Davies to Make Deep Space Electronic

Imaging Systems Capable of Precise Mapping of Mars ........... 34

Important Scientific Results at the Moon, Mercury, and Venus Enabled

by Davies' Techniques and Optical Design Contributions........ 40

On to the Outer Solar System .................................. 42

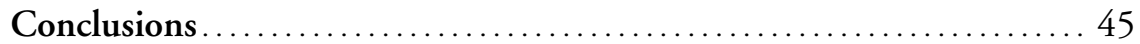

References Cited ........................................ 46 



\section{Figures}

1. Davies and Friend in Antarctica .......................... 26

2. Mariner 4 in 1965 Discovers a Lunar-Like Mars .............. 31

3. Mariner 6/7 Instrument Platform........................ 33

4. Mariner $6 / 7$ Digital Vidicon Cameras ...................... 34

5. Mariner 6 Confirms Cratered Surface ...................... 35

6. Mariner 7 Explores the Edge of the Martian Seasonal Cap...... 36

7. Mariner 7 Surveys the Globe of Mars on Approach ............ 37

8. The Fundamental Reference Point for Mars, Airy 0 .......... 39 



\section{INTRODUCTION}

Merton Edward Davies (1917-2001) was a major contributor to U.S. space efforts from when he first became affiliated with the RAND Corporation in 1947 until his death in 2001, at which time he still maintained his office at RAND. In 2000, he was honored as one of the Pioneer Founders of National Reconnaissance. In 1998, he was elected a Fellow of the American Geophysical Union (AGU) for his planetary mapping work.

Our purpose in writing this paper is to bring these achievements into perspective, not only out of respect for a man with whom we both worked closely for decades, but also as a window into an important period in American history and into RAND's role in it. Davies' early role in the successful development of highly classified satellite photography as the Cold War was escalating is presented first (by Augenstein). Davies' remarkable second career in exploring the planets follows (by Murray). This paper is the very expanded written version of an oral presentation by Murray at a commemorative session of the AGU in December 2002.

Preparation of this publication has been a labor of love as well as duty. It was a privilege to have shared with Davies the highs and lows of America's response to the opportunities and the challenges afforded by space exploration. We hope that this publication will help others reconstruct those "purple" decades as well as to appreciate the number of Davies' professional contributions. 


\section{NATIONAL RECONNAISSANCE CAREER (1947-1970)}

\section{Mert's Early Years at RAND}

To better appreciate Davies' career during this period, it is informative to discuss the contextual framework relating to issues of intelligence and imagery within which his contributions took form. A goal of the subsequent discussion is therefore to relate briefly circumstances shaping those very influential contributions. As we will see, these contributions constitute a lasting legacy of work with deepseated implications for the conduct of the United States in the Cold War era.

RAND was chartered in 1946 (strictly speaking, it was Project RAND, 1946-48, before incorporation in 1948) to support the United States Air Force (USAF) with scientific studies to help the Service in its designated roles for national security and the national well-being. RAND began its major participation in space efforts in 1946, with the publication of a requested (by the then Army Air Force) multiauthored work on "a world-circling spaceship," paralleling less well known analyses of satellite feasibility done at Martin and North American Aviation. (A comprehensive account of RAND's early space work may be found in Augenstein, 1995.) The 1946 RAND study started a series of detailed studies of space activities, particularly satellite analyses, which, as we will see, contributed significantly to United States space goals over the next decades.

Davies came to RAND in July 1947, after an earlier period in which he was a mathematics instructor at local academic institutions and then a chief lofter for Douglas Aircraft. Lofting, a now nearly forgotten arcane art in aviation, was a set of techniques for drawing full-scale plans for the aerodynamic shapes desired so that the structures involved could actually be built; to do so, for example, required capabilities for drawing smooth curves through a limited 
number of appropriately fixed points (capabilities relevant, incidentally, to cartography).

After its early work on satellites, RAND broadened its roles into general studies of missiles as well-that is, on the continuation of research on rockets and ramjets undertaken in Germany in WWII. It is not widely known that the preliminary design of the NAVAHO missile, ramjet driven, was done under RAND's aegis in 1947-48 (Augenstein, Wilson, et al., 1948). For roughly his first half dozen years at RAND, Davies, as a carryover from his Douglas days, was one of the central participants in these general RAND studies. ${ }^{1}$ An extensive collaboration between RAND and the Battelle Memorial Institute (under RAND subcontract) was undertaken on space and missile-related engineering issues. Via a lengthy series of reports, Battelle conducted several dozen studies on rocket, supersonic aircraft, and missile fuels, and on the materials of construction for space vehicles and for very high speed atmospheric vehicles. (It is interesting that the first study to appraise the value of titanium and titaniumbase alloys as construction materials was done in this Battelle subcontract, thus suggesting the value of titanium for such vehicles as the later SR-71 and its limited use on even earlier vehicles.)

The role of RAND in this extensive RAND-Battelle collaboration was to integrate the Battelle studies into synthesizing studies of missiles and spacecraft. Davies was an important player in these synthesizing studies, participating as a coauthor in a number of key investigations on how to select materials for missiles; how to analyze structures and weights for guided missiles; how to compare, in a variety of ways, the promise of ramjets and rocket missiles; how to compare the status of early (i.e., 1952) U.S. and USSR surface-to-air missiles; and how to estimate, using this inventory of data, U.S. strategic bombing capabilities of alternative U.S. force compositions (Davies, Culp, and Higgins, 1950).

\footnotetext{
${ }^{1}$ Bruno Augenstein thanks Rick Bancroft of the RAND library for furnishing a complete bibliography of Mert Davies' RAND publications. Thanks are also due to Malcolm Palmatier and Donald Stevens for helpful comments on an earlier draft of the 1947-1970 section.
} 


\section{The Cold War Intensifies, the Needs for Intelligence Burgeon}

While all this work was going on, into the early 1950s, international events were unfolding which shaped Davies' career for roughly the next decade and a half. The Cold War deepened, driven by the Berlin blockade of 1948-49, the Soviet atomic bomb of 1949, and fragmentary but persistent intelligence reports on Soviet missile and space work, on progress on jet aircraft, on the general pace of development of Soviet military forces, especially strategic forces, and on Soviet rapid acquisition of force capabilities of all kinds. Suddenly it became imperative that the United States acquire detailed and comprehensive intelligence on the Soviet buildup and its threat potential. Captured WWII German material on the Soviet Union quickly proved inadequate. In addition to customary espionage means, more dependence evolved into new instrumentalities for critical and timely reconnaissance and intelligence gathering-instrumentalities relying more and more heavily on overhead observations of several critical kinds. This next phase of Davies' career at RAND was largely devoted to fundamental investigations into aspects of overhead reconnaissance, a number of them in collaboration with Amrom Katz, a RAND researcher hired in 1954 from Wright Field and an expert in many aspects of photographic reconnaissance.

By early 1954, a number of U.S. tools for overhead reconnaissance were already being exploited, or were in the critical planning and development phase. ${ }^{2}$ These tools included use of converted bombers; development of new, specialized reconnaissance aircraft; use of unmanned balloons as reconnaissance instrument platforms; and the use of satellites as reconnaissance platforms. RAND, and Davies in particular, was intimately involved in the latter two tools (balloons and satellites). Brief commentaries on the first two tools provide context for RAND's involvement in reconnaissance activities.

\footnotetext{
${ }^{2}$ A useful reference on a broad range of declassified reconnaissance issues is a series of publications and electronic briefings by Jeffrey T. Richelson (The National Security Archive). These include both abstracts of critical documents and in some cases the full document, with sources including responses to Freedom of Information Act requests and searches of the National Archives.
} 
By the late 1940s, the United States was using converted fighters and bombers to fly missions around the periphery of the Soviet Union, using late-technology cameras that allowed high-acuity longrange oblique photography to produce detailed imagery of areas relatively near, but inside, Soviet borders. Even more adventurous were actual overflights of the Soviet ground space to produce interior imagery of military facilities and installations, to monitor Soviet activities. These flights were also aimed at inducing the Soviets to turn on their radars. Both the imagery and the induced electromagnetic signals were to aid, as one key objective, the Strategic Air Command (SAC) in designing optimum penetration routes into the Soviet heartland seeking critical targets. All these converted fighter and bomber missions were held extremely closely by USAF, and, with few exceptions, RAND had very limited contemporary cognizance of them. ${ }^{3}$

The story of the U-2 is now relatively well known, but the prehistory of the U-2, more relevant here, is less widely appreciated (Miller, 1988). In the fall of 1952 Major John Seaberg at Wright Field began to develop the specifications for a very high altitude recce aircraft—specifications which were warmly received at the highest levels of USAF. It is not clear how much information passed between Seaberg's office and concurrent efforts in ongoing Cold War overflights. A go-ahead was given to solicit proposals - solicitations that Seaberg forwarded to three small aircraft companies (Bell, Fairchild, and Martin), deliberately excluding large companies like Douglas and

\footnotetext{
${ }^{3}$ Much, but by no means all, of the history of these missions has been declassified. The extensive NRO symposium proceedings (2 volumes) on "Early Cold War Overflights," published in 2003, focuses on the 1950-1956 period, whereas overflights in the 1940s, when a number of misadventures occurred, are not documented there. Also, records of some missions seem to be absent. The converted bomber overflights overlapped the start of U-2 missions, and the aircraft performance achieved is noteworthy. For example, the converted RB57 aircraft reached mission exit altitudes of about 68,000 feet-within roughly a mile or so of the later U-2 capability. The converted bomber missions also could carry larger cameras-especially on peripheral missions - than the U-2. It is not surprising, consequently, that both United States and British Air Force personnel were initially not impressed with CIA U-2 operations, regarding them as not superior to their own results, albeit raising fewer political issues, perhaps, than ostensibly military aircraft prompted.
} 
Lockheed because he felt the large companies would not emphasize a small-production project, which a specialized recce aircraft would inevitably be. Bell won the competition in May 1954 with a model then designated as the X-16. It incorporated, for example, a 12-inch focal length search camera and a 36-inch focal length technical intelligence camera. Construction of the X-16 got under way in September 1954.

In the meantime, an utterly fortuitous event had transpired in late May-Kelly Johnson of Lockheed had been leaked news of the Seaberg competition and had made an unsolicited proposal to Seaberg for an aircraft which eventually became the U-2-a proposal rejected by Seaberg because it "did not offer any serious advantages over the designs already reviewed. . . .," whereupon USAF turned down Johnson's proposal. Johnson, however, pursued his case, ultimately persuading key senior members of Eisenhower's administration (Killian, Wilson, Dulles) that his project was worth pursuing. Eisenhower agreed, and the CIA, headed by one of the trio of senior members (Allen Dulles), decided to fund what was by then called the U-2. After a while, USAF decided to let the CIA handle the special recce aircraft program by itself. After a few months of serving as a "cover" for the U-2, the X-16 was finally cancelled in October 1955, with the first aircraft nearly complete (but some two months after the U-2 had first flown).

There is little question that the X-16 would have performed essentially as the U-2 did (its planform was similar to that of the U-2, but it had two engines), and that it would have accommodated the advanced cameras later associated with the U-2 program (e.g., the "Type B" camera).

In fact, two aspects of the X-16 and U-2 programs proved relevant to the subsequent RAND involvement with recce programs (RAND had no significant knowledge of these specific aircraft programs at the time). The first aspect is the further broadening of camera technology, already well under way in the converted bomber program. The second aspect is the rapid development of new "compartments" for protection of information, brought about in substantial degree by CIA involvement. The TALENT compartment was 
established in the mid-1950s to protect both the U-2 collection system and its intelligence product. An executive directive of August 1960 broadened TALENT to include all nationally tasked overhead reconnaissance, with a subcompartment, KEYHOLE, for satellite information. The compartmentation programs here initiated were codified in September 1961 by the establishment of the National Reconnaissance Office (NRO), charged with coordination of "the research and development, production, and operation of satellite and aerial reconnaissance systems used in overflights of the Soviet Union and other nations." These extremely tightly held compartments and their detailed information were for a significant time not available to RAND personnel (although RAND was consulted on the possible political issues of "special aircraft overflights," for example), so that early U-2 and satellite operational knowledge and recce were effectively unavailable to contemporary RAND researchers, including Davies, for a period of time alluded to again later.

In contrast to the programs just described, RAND personnel had significant involvement with balloon recce programs, and worked from about 1949-50 and subsequently on many issues having to do with this form of pre-hostilities reconnaissance (which many at the time thought to be a nearer-term possibility than either aircraft or satellite systems). RAND balloon work contributed to Air Force projects GOPHER, MOBY DICK, and GENETRIX, with the latter being the actual balloon recce operations. Additionally, a small subsequent program, 461L, was undertaken as part of the balloon recce program-which thus overlapped U-2 operations. In all, 516 cameraladen balloons were launched, mainly from Turkey and other sites in Western Europe, with 40 recovered and producing photographs covering a significant fraction of the Soviet Union (about 2 million square miles) with imagery of useful quality. The midair snatch of physical payloads in the later CORONA satellite program had its antecedent in balloon payload recovery. Cameras used in the "stableattitude" balloon recce systems were antecedents of later satellite cameras; and the chief designer of critical balloon cameras later was a chief designer of the CORONA imaging system (a panoramic camera). In any case, the general balloon recce work was accessible to 
RAND, and in particular to Davies, who played a prominent role in execution of portions of the balloon recce program.

Finally, we come to satellite recce-the field in which RAND had been the United States' foremost flag-bearer since its pioneering report of 1946. Major satellite studies were issued in 1947, 1951, and in March 1954 (the last being the "Project Feedback Summary Report"). Davies played a significant role in moves RAND made in 1951 to formally include satellite reconnaissance systems as part of the Air Force's array of development plans for overhead imagery to underpin intelligence acquisition. The Feedback study of 1954 (Lipp and Salter, 1954) was a landmark engineering study which formed a preliminary working blueprint for the early space reconnaissance program (in fact, one of the two principal authors of the Feedback study [Salter] later was one of the chief architects of the successful 1956 bid by Lockheed to actually develop reconnaissance satellites).

Coincidentally, RAND in 1954 published a precis of its intercontinental ballistic missile (ICBM) studies (Augenstein, 1954) briefed to the von Neumann TEAPOT Committee in late 1953. That briefing provided the committee with the blueprint it advocated for pursuing the development of the ballistic missiles that would become the basic Delta, Atlas, and Titan space launch systems which today still underpin the U.S. space launch capability exclusive of the Space Shuttle. ${ }^{4}$ The ICBM studies treated all critical subsystems, including reentry phenomenology, and showed incidentally how satellite reentry was generally easier than ICBM reentry, findings that would play an important role in subsequent satellite recce issues.

\footnotetext{
${ }^{4}$ The document SM21 is a highly abbreviated account of a four-hour briefing given to the TEAPOT Committee in December 1953. The briefing included relatively full accounts of detailed thermonuclear weapon future design options and a broad range of intelligence findings; these options and findings were almost completely eliminated in the written document, so that wider distribution could take place. One outcome of RAND's ICBM work was that RAND was in fact the DoD's first choice to perform the systems engineering job for the ICBM; the proposal was rejected by the then president of RAND. The originally top secret SM21 has been described by the missile-age historian Donald MacKenzie, in his 1990 book Inventing Accuracy: A Historical Sociology of Nuclear Missile Guidance, as "the single most crucial document of the (missile) revolution."
} 
The Feedback study (two volumes) proposed a television system with applications to reconnaissance (recognition of ground scenes), to mapping (location of ground data), and to weather analysis. Some 200 people were involved in the study. ${ }^{5}$

\section{Davies Begins His Reconnaissance Satellite Studies}

The Feedback study marked Davies' first foray into specific issues of satellite imagery and space photography. A key factor in space reconnaissance utility is of course interpretation of satellite photographs. Because we had no satellites aloft producing imagery of the quality aimed for in Feedback, a central concern was to simulate satellite photographs and undertake interpretation of those simulations. This required a complex series of laboratory investigations at the Radio Corporation of America (RCA), the subcontractor to RAND for the electro-optical television operational system envisioned. As the Summary of Feedback notes: "The overall conclusion to be drawn from studies of simulated satellite television pictures is that reconnaissance data of considerable value can be obtained, and that complete coverage of Soviet territory with such pictures will result in a major reversal of our strategic intelligence posture with respect to the Soviets." Davies was the author of the two critical documents that discussed and supported this claim: the first a brief report entitled "Feedback simulation pictures taken at RCA," in December 1954; the second an extensive (155 pages) report similarly titled, in September 1955 (Davies, 1955). These two documents mark, therefore, Davies' first critical considerations of techniques of imagery, mapping, and interpretation that were to be his main preoccupations for the remainder of his career.

After a brief interlude of attention to tactical ballistic missile development and, with Amrom Katz, discussion of general problems of

\footnotetext{
${ }^{5}$ Of these roughly 200 people, about one half were from RAND and the remainder from industrial subcontractors to RAND. Each RAND individual had a specific assignment. For example, Bruno Augenstein produced the section on Development, Scheduling, and Cost Estimates, based in substantial measure on comparable work just done for RAND's ICBM studies.
} 
USAF technical intelligence requirements and objectives, Davies in 1957 was one of the two principal authors of a seminal RAND study issued November 12, 1957 (RM-2012, Davies, Katz, et al., 1957) and supported by nine authors in special subfields- $A$ Family of Recoverable Reconnaissance Satellites. The Soviets launched their Sputnik on October 4, 1957-an occasion for pulling together and accelerating formal publication of the study and RAND recommendations to the Air Force on revisions to the then current Air Force reconnaissance program.

This study was aimed at providing both an early and a continuing photographic capability to augment the WS-117L program (the designation given to the military reconnaissance satellite system under development by Lockheed, winner of the 1956 contract award by USAF). The work summarized in RM-2012 was the culmination of a yearlong effort and had already been widely briefed to the Air Force in the summer of 1957. The briefings helped lead the Air Force to consider the message of RM-2012 as a 117L requirement, pursuant to RAND's recommendations. The RAND proposal differed from the then current $117 \mathrm{~L}$ program in several respects:

- Use of a spin-stabilized payload and camera stage.

- Use of a different (and lesser capability) upper stage on the THOR booster first stage.

- Recovery of the entire payload stage (the then planned $117 \mathrm{~L}$ was the basic television data-transmission system described in the Feedback report).

- Most important, RM-2012 suggested speeding up the pace of the reconnaissance program, postulating an initial operational capability (IOC) of January 1959 for its immediate first capability.

The goals of these departures from 117L were primarily to have a modest resolution (about 60 feet, somewhat better than the initial $117 \mathrm{~L}$ system was to provide) system in operation before the then cur- 
rent $117 \mathrm{~L}$ planning dates, using a 12 -inch focal length special camera, while providing for follow-up systems giving better resolutions appropriate to cameras of 36-inch and then 120-inch focal length. The $117 \mathrm{~L}$ system also featured progressively better resolution in subsequent systems.

The interested reader will find a discussion of the history of spinning cameras in Appendix B, pages 33-39 of RM-2012, including the refinement proposed by Mert.

\section{National Intelligence Needs Lead to the CORONA Satellite Program}

At the same time, and wholly unbeknownst then to RAND, Sputnik had also prompted strong reactions relevant to reconnaissance within the highest offices of government. There is here a rather convoluted history, which warrants more attention than can be given at this point, including interactions between the Air Force and the "national authorities." Already on October 24, 1957, the senior Presidential Board consultants discussed the two new major reconnaissance systems then under consideration. One was the manned CIA aircraft, "to be designed for greatly improved performance and reduced radar cross-section"; early studies had already suggested the safe operational survival of the U-2 to Soviet defenses might only be $2-4$ years. This aircraft, under CIA's OXCART program, was first the A-12 and then later in modified form became the SR-71. The second system was USAF's $117 \mathrm{~L}$ program. The Board was concerned that mid-1959 was the very earliest possible operational date for either system; the need for an "interim" reconnaissance system was stressed. The Secretary of Defense responded on November 13, 1957, by authorizing the acceleration of $117 \mathrm{~L}$ to proceed "at the maximum rate consistent with good management." A specific subsystem of 117L using the THOR booster would therefore be separated from the general 117L program "to ensure the best prospect of early success." It would be run by a joint CIA-USAF team, with the active involvement of the newly created Advanced Research Projects Agency (ARPA), placed under CIA security blankets à la the covert U-2, and designated project CORONA. Along with this program separation, a series of cover actions was undertaken to make it appear, in early 1958, that this 
interim system was actually cancelled-an ostensible cancellation that astonished the great majority of USAF personnel, as well as RAND individuals who had worked on RM-2012-before a very few individuals (none of them from RAND) were quickly cleared for the then extremely covert CORONA program.

The earliest CORONA plans included a Fairchild hybrid proposal for spin stabilization of the payload-a camera of 6-inch focal length using the readout concept of 117L. However, physical recovery of the film was quickly seized on as the most promising "interim" approach. After serious problems with the Fairchild proposal emerged, interest began shifting to an earth-stabilized payload using a competitive design by the Itek Corporation and using a longer focal length (24-inch) camera based on a previous design (i.e., on the Boston University Hyac camera). After a brief period in which the Fairchild proposal was envisaged as being early-operational, and the Itek proposal as a follow-on, the Fairchild proposal was dropped altogether. Thus, by the spring of 1958, the interim CORONA system proposed to use the THOR-boosted AGENA upper stage (a large Earth-stabilized stage developed by Lockheed); physical recovery vehicles; greatly improved balloon program-model cameras; and GENETRIX-developed techniques for payload retrieval (i.e., air snatch of the parachuting deorbited payloads). The subsequent history of CORONA is now well documented in unclassified literatures (Greer, 1973; McDonald, 1995; Day, Logsdon, and Latell, 1998; Taubman, 2003), is now widely known and easily available, and needs little additional consideration here. ${ }^{6}$

\footnotetext{
${ }^{6}$ Taubman's description, a generally well written and reasonably comprehensive account of events, nevertheless has a pronounced failing not uncommon to many such histories-a strong imbalance of emphasis. As just one example, the officials associated with various CORONA programs and projects are very well represented and in many instances interviewed, whether their role was unique or routine, critical or customary. Contrariwise, the small cadre of highly skilled Lockheed engineers and technicians who actually built CORONA is essentially unrecognized and unheralded. These are the individuals who planned, conceived, designed, built, and tested the complex interrelated array of camera, film transport and storage, and reentry components that had further to be assembled and integrated with the vital communications, command and control, and telemetry functions of the AGENA spacecraft to produce the operational CORONA. Program officials could make,
} 
However, it is of interest to assess the relationships of the subject matter of RM-2012 and the CORONA program as it evolved. As just noted, CORONA differed from the RM-2012 payload proposals in basic ways listed below:

\begin{tabular}{lll}
\hline & CORONA & RM-2012 \\
\hline Upper stage & AGENA & Vanguard stage \\
Camera & Earth-stabilized 24-inch focal length & Spinning 12-inch focal length \\
Reentry & Film only & Entire payload stage \\
Recovery & Air snatch of parachute & Water impact (no parachute) \\
\hline
\end{tabular}

Certain features of both systems were conceived independently, including use of the THOR booster. More important, RAND apparently conceived the very critical steps of recovering the recce product and of accelerating the recce program-two operational features making an enormous difference in the actual conduct of space recce in the immediate future. And even if RAND's specific payload recommendations of RM-2012 were not followed in any major way, the CORONA camera design ultimately evolved into one in which a special drum assembly is continuously rotated, thus avoiding use of certain reciprocating mechanisms in the original camera. The whole camera was never spun.

Nevertheless, it is amply clear that RAND played a most significant participatory and initiating role in the acceleration and recasting of the then extant reconnaissance satellite program, and that RAND studies provided exemplars for encouraging others' efforts. The importance and utility of this role should be emphasized and widely appreciated-RM-2012 provided an early, independent proofof-principle analysis of a revised satellite reconnaissance program, assessed to be responsive to concerns raised and actions taken starting in October-November 1957 at the highest governmental levels.

very generally, no recommendations on how the agreed-on goals for CORONA were to be attained, although they could specify what goals were sought. This all had to be done de novo, with no prior base of experience. The problem solutions were models for all subsequent U.S. film recovery satellites in the next decade. The Lockheed team (and as well the ancillary teams at Itek and General Electric) is vastly underrepresented in accounts of salient events and critical responsibilities for producing a workable CORONA system. 


\section{CORONA and RAND: Interactions and Issues}

It should not be too surprising, therefore, that many (in USAF, for example) who were familiar with RM-2012 in the fall of 1957, but who were not cleared for CORONA until much later, tended to regard CORONA as a "natural" operational evolution of the specifications of RM-2012, being largely unaware of the extensive ferment in government leading to CORONA - a ferment in which the "proof-of-principle" role of RM-2012, and Davies' proposals for modified imagery acquisition tools, were of salutary importance.

Thus, the first official CIA history of CORONA in 1973 notes RAND's role in bringing about the $117 \mathrm{~L}$ program-but makes no mention of an influence on CORONA such as the contemporaneous RM-2012 reflects. Indeed, a point suggested in the most encompassing history of CORONA, by RAND's Bob Perry, ${ }^{7}$ is that the same program can be seen from many varied perspectives, à la the wellknown movie Rashomon, a theme also familiar from the book The Alexandria Quartet.

Two points now warrant consideration regarding RM-2012 and Davies' central role in promulgating the messages of the seminal document:

- Why the absence, in the first CIA CORONA history, of identification of and commentary on RM-2012?

- Why did RM-2012 succeed so eloquently in conveying its intended lessons, in the face of abortive earlier attempts at RAND to deliver comparable messages?

Regarding the first point, one can do little but surmise 30 years after the fact. From the CIA's vantage point, it seems likely it was more attuned to issues raised by national authorities rather than by the Air Force, and that an "independent thrust" was necessary to pro-

\footnotetext{
7 The account by Perry relies predominantly on documentary sources, rather than emphasizing interviews of involved personnel. It is of course not uncommon for interviews to exhibit significant memory lapses of those interviewed, and sometimes unintentional exaggerations of roles, when compared with extant written sources of information.
} 
duce changes at the national level-i.e., it was not the first time, or the last, that the CIA felt that it was neither necessary or sufficient for an Air Force position to enforce a national position. Such an "independent thrust" may have had several components, including the following:

- The USSR August 1957 ICBM launch, and more forcefully the October 1957 Sputnik launch, reinforced and amplified the national criticality of estimating USSR capabilities and made that a national priority.

- Influential senior presidential advisors were now treating the issues of the U.S./USSR strategic competition on a par, at least, with the previous priority of warning. The 1955 Air Force General Operational Requirement (GOR) 80 for continuous surveillance of preselected areas was seen, by the Air Force and national authorities, as a fine goal, but not necessarily mandatory, contrasted with a periodic sampling of capabilities and capacities. In particular, the national authorities were beginning to appreciate fully the importance of neither underestimating nor overestimating the products of USSR military research, development, test, and evaluation (RDT\&E) programs, thus creating new target priorities.

- The intelligence culture had become accustomed, in 1956 and 1957 , for example, to tolerating relatively small delays in gathering capabilities intelligence-if, e.g., the recce products were of exquisite quality. After all, following the start of U-2 missions in 1956, even this relatively fast producer of intelligence could take in excess of one day under the best of circumstances to produce initial recce information, from launch in Pakistan, recovery in Norway, shipment of recce take to the National Photographic Interpretation Center (NPIC) in the Washington area, and then first review of the film. Such a time cycle was quite consonant with the time cycle of the first satellite film recovery schemes. 
- With the U-2 estimated from the start as having a potential operational life of 2-4 years, there were few qualms at its possible replacement with a system-film recovery satellites-having comparable delays.

- The CIA history remarks that the CORONA program was pursued through oral briefings only during a crucial period-i.e., that there are no official records in CIA's Project CORONA files bearing dates between December 5, 1957, and March 21, 1958.

Components such as these may very well have given the CIA the 1973 view that such factors, other than an Air Force and RAND RM-2012 role, were instrumental in national acceptance of schemes for film recovery from satellites. There is now no way of establishing definitely whether, in the absence of such factors, an independent Air Force position based on RAND's views could have been solidified into a decisive national position for accelerated film recovery schemes.

However, it is noteworthy that in Davies' year 2000 NRO citation, to be made explicit subsequently, there occurs this statement: "He . . collaborated in the film recovery satellite proposal adopted by the USAF that became CORONA." This proposal was of course that of the RM-2012 work; and the statement thus very appropriately reflects Davies' efforts and the attendant Air Force position in shaping the national response.

Regarding the second point-the unique success of RM-2012 in influencing the consequent Air Force position-we need to remember that brief antecedent studies had laid significant parts of the groundwork for RM-2012 and its vigorously briefed conclusions and recommendations. But these antecedent studies had either a negative impact or no impact on the Air Force, let alone on the national authorities. ${ }^{8}$ This is where the true profound impact of the RM-2012

\footnotetext{
${ }^{8}$ Two major antecedent studies at RAND can be cited (there were also comparable studies done outside RAND). While film recovery had been briefly studied during the preparation of the 1951 RAND satellite report, it had then been judged as taking more R\&D and a
} 
work can be measured, and where the Davies, Katz et al. product is an exemplar of success.

It seems that at least four powerful reasons can be adduced for the unique success of RM-2012 and its lasting profound effect on the national reconnaissance scene. None of these reasons is by itself sufficient for success; and all four were necessary, in my view.

- The system study format of RM-2012. The reasons for previous studies to languish had been absorbed. In groundbreaking studies, the instinctive reaction of audiences is the "Yes—but what about so-and-so?" question. If the study personnel hesitate or falter on such questions, the momentum and acceptance for the results quickly erode. RM-2012 anticipated in its text the preponderance of such plausible questions-the result of the formation of an 11-person multidisciplinary team of researchers. The awareness of this team that the anticipated byplay with the

\footnotetext{
longer time than the readout system pursued. In the spring of 1956 Dick Raymond proposed a film recovery satellite, to "maximize information returns," and RAND made a formal recommendation to USAF to pursue that option. USAF reacted violently against the proposal, leading RAND (to the consternation of many of its researchers) to withdraw that recommendation. USAF objections were based in part on a recovery system not meeting existing requirements, and on some presumed technical shortcomings of the proposal. Ironically, and with delayed justice, Raymond was honored some three decades later by the NRO as "a pioneer in reconnaissance." A very significant antecedent report came out in June 1956-RAND publication RM-1811, Physical Recovery of Satellite Payloads-A Preliminary Investigation, by J. Huntzicker and $\mathrm{H}$. Lieske. This report was apparently the first to suggest that physical recovery of film might beat out imagery readout in schedule, that film could survive reentry heating (using calculations much like those already used to suggest that warhead components could survive reentry), and that slowing the reentry vehicle via parachute could ease problems of maintaining the structural integrity of the payload vehicle as well as aiding recovery. USAF paid no appreciable attention to RM-1811. However, it is evident that RM-1811 was one major incentive encouraging the Davies and Katz team to undertake the work leading to RM-2012. In one significant respect the two reports differed-RM2012 , in order to meet weight goals, eschewed the terminal parachute and assumed, correspondingly, that the reentry vehicle would make a water impact at about 400 feet per second. The industrial contractors who learned of the findings of RM-2012 early on were wholly unconvinced that a relatively lightweight structure could survive water impact at that velocity, and conceived a heavier system with a terminal parachute-which provided two gains, in their eyes: the earlier balloon recovery system could be exploited again, and the increased weight made the use of the Lockheed-developed AGENA spacecraft mandatory, so that this spacecraft, developed for the $117 \mathrm{~L}$ system, could be used for the alternative recovery option also.
} 
audience could and should be built into the study itself made a pronounced difference.

- Ambitions of the Air Force. The intent of the Air Force had all along been to incorporate within its structure operational satellite systems. The message of RM-2012 was that such an operational era could be brought much closer via the type of program acceleration proposed-a message very appealing to the Air Force. In the event, of course, the resulting program was handled as a cooperative CIA-Air Force program, and the later establishment of the NRO codified the loss of unilateral full control of specific satellite programs by the Air Force.

- RAND personnel in RM-2012 work. The nine subsystem specialists (Buchheim, Burke, Gabler, Garber, Gazley, Heffern, Huntzicker, Lieske, and Masson) were all experts in their fields, in a few cases being recognized as national authorities. The team leadership by Mert Davies and Amrom Katz was indispensable in very different ways. Katz was brash, knew his way inside the Air Force as an institution, appreciated what buttons needed pushing for results, and could peg his briefings to any appropriate level. Davies was disciplined, elegant, thoughtful, thorough, and inventive. The interplay between these two RM-2012 leaders built the complex framework of requirements, the technical solutions needed to satisfy these requirements, and the management/organizational possibilities to further the enterprise. The team leadership thus constructed an integrated package the Air Force could embrace in its entirety and run with. Few RAND system studies ever achieved the level of effectively "turn-key package" reflected by RM-2012, a level directly attributable to the leadership qualities of the Davies-Katz complementary team.

- The mood of the times. This reason was discussed in the previous comments on the CIA 1973 history. RM-2012 and its associated actions through the summer and fall of 1957 came at a cusp in history when senior authorities were casting about for a procedural vehicle they felt could be responsive to the mood of 
the times. The apparent receptiveness to the RM-2012 prescriptions for action was amplified by these circumstances, substantially.

\section{The Early Years of CORONA and Davies' Contemporary Career}

Thus, RM-2012 came at the right time, with a highly embraceable message. The Air Force welcomed it, for reasons alluded to above, and proceeded to take responsive actions at a swift pace. The result was that a singularly important contribution to national reconnaissance was made by the Davies-Katz team in the RM-2012 recommendations.

One further point warrants consideration: Why the spinning payload of RM-2012? In 1964, Davies received a patent for such a spinning camera system. It is clear that between them, Davies and Amrom Katz were cognizant of the bulk of camera developments in the United States, with the exception of detailed knowledge of some highly classified articles in compartmented programs. ${ }^{9}$ A number of options are noted casually in RM-2012, only to be assumed to be too complex, too heavy, or to take too long to implement, and so are set aside for later consideration. For example, pages $\mathrm{v}$ and vi of the RM2012 preface read, "an interesting alternate to the first system (12-in. focal length) would start with an existing Baker 24-in f/5.0 telephoto lens, easily capable of 100 line/mm ... [and] would yield a ground resolution five times better than the preceding 12 -in. system ... (but) exercise of this option ... should follow, not precede, testing of the

\footnotetext{
${ }^{9}$ One interesting example of this compartmentation is appropriate. The suggestion of a 120 inch focal length camera as the final future member of the camera family of RM-2012 was regarded as "adventurous" by both the RAND team and by essentially all of the audiences for RM-2012 briefings. For example, the longest focal length planned in the $117 \mathrm{~L}$ program was just in excess of one half this focal length. But, as a matter of history, a massive camera had been flown in a converted RB-57 Canberra about two years earlier, with high-acuity longrange oblique photography as the primary mission. This device had an $\mathrm{f} / 11$ lens, weighed 2,400 pounds, had a focal length of 240 inches, and was designed to get good imagery from a slant distance of some 80 miles. This camera was later used to perform some definitive experiments on various aspects of long-range photography. The camera, used on some of the most highly compartmented missions of the Cold War, was known to very few contemporary individuals, however.
} 
simplest possible system." The Baker system mentioned here has a familial resemblance to the Itek 24-inch system put on the first CORONA, and requires attitude stabilization.

Part of the situation here seems to be that while Lockheed, for example, was well-informed on contemporary RAND studies, important details of Lockheed's programs were not, in some instances, adequately accessible to RAND. ${ }^{10}$ Included in these details were likely significant information on the pace of progress on the AGENA upper stage, and on the implementation of horizon sensing and 3-axis earthoriented attitude stabilization of this high-payload-weight upper stage. Substantial discussion of horizon sensing and 3-axis stabilization was included in RAND's 1951 and 1954 satellite reports, but not updated. Better information on such issues would probably have produced more concerted attention in RM-2012 to these more complex, but also substantially more competent, alternatives to the options given first priority in that document-options very strongly driven by the pronounced payload-weight constraints produced by selection of Vanguard hardware as an upper stage and by the presumed need for a very early IOC, which led to elimination of a number of program options in RM-2012. Thus the focus on the spinning camera in RM-2012 was effectively the result of accommodating to the emphasis on Vanguard hardware, which seemed to promise an early IOC, but concurrently had a severely compromised payload capability, which mandated the selection of the proposed 12-inch focal length spinning camera because of weight constraints. It appears

\footnotetext{
10 This comment, and some subsequent comments, are based on the fact that Davies' and Augenstein's careers at RAND overlapped, and even for the nine years when Augenstein was not at RAND, contacts persisted. In the spring of 1958, Augenstein left for Lockheed, where he became Scientific Advisor to the Space Division, working inter alia on CORONA, the AGENA spacecraft, other satellite programs, and managing a preliminary design on a highresolution reconnaissance satellite which ultimately became the GAMBIT system (KH-7). In the fall of 1961, Augenstein became Special Assistant and Director for Intelligence and Reconnaissance, an office in the Directorate of Defense Research and Engineering under the Secretary of Defense. At that time, this office had programmatic oversight over the National Security Agency, the National Reconnaissance Office, the Defense Intelligence Agency, and the various military department intelligence activities. For this work, Augenstein was awarded the Distinguished Public Service Award, DoD's highest civilian award. During this nine-year period, Augenstein was well aware of Davies' activities for USAF and the NRO.
} 
plausible that with such information RM-2012 might well have produced proposals mirroring many aspects of CORONA's actual final systems implementation - a further bonus for its already realized most critical impact as an independent, proof-of-principle spur to an accelerated national satellite reconnaissance program featuring recovery.

In any case, we have here a defining seminal link between Davies' decisive role in RM-2012 and the critically important CORONA program - a program in which ultimately 121 satellites would orbit between 1960 and 1972, acquiring roughly 800,000 pictures on 2.1 million feet of film, at resolutions toward the program end of the order of 5 feet on the ground. The pictures were of supreme national importance on all issues of the strategic competition between the United States and the Soviet Union, including the trend toward arms controls verifiable by remote satellite reconnaissance. It is noteworthy that the total coverage of USSR land mass by all U-2 missions together was exceeded by the first successful CORONA flight, albeit at poorer resolution.

After the CORONA program was implemented in the spring of 1958, under the rigid CIA compartmented access restrictions initiated in the U-2 program, and with joint CIA/USAF roles in implementing the program, limited numbers of individuals were given access to the program in the next several months. Davies (and Amrom Katz) was not among these individuals for an uncomfortably long time. However, Davies and Katz had strong intuitions that something important was going on related to RM-2012, even if they could not now contribute to it, and they were openly skeptical that the much publicized "cancellation" of the so-called "interim" system was anything but a cover for the "something important" they felt was under way. Such reservations did not speed up their access to the CORONA program. Reasons given for this early denial of CORONA access seem in retrospect to be scarcely cogent. There were indeed concerns about the compartmentation process in CIA and DoD programs fairly early on. In 1977, a CIA study was undertaken, the bulk of which has been recently declassified (CIA, 1977): "A critique of the codeword compartment in the CIA"-one of the 
conclusions of the report-is that "the present costs of compartmentation in confusion, wasted manpower, less meaningful intelligence, and enhanced risk of intelligence failure could be ameliorated, if not eliminated." The dilemmas posed by a compartmentalization process that initially screens out dedicated, singularly innovative contributors from an emerging critical enterprise are reflected in the early RM2012 and CORONA interactions. ${ }^{11}$

The remarkable train of events here at play should be noted. If Kelly Johnson had not fortuitously injected Lockheed into the Seaberg competition; if Seaberg had not rejected the Lockheed proposal, leading Johnson to pursue his plan elsewhere; if that pursuit had not culminated in the approval of a CIA-funded program; and if that CIA program had then not induced Air Force abandonment of the X16, an early special aircraft overflight program under Air Force auspices would likely have resulted. Under more "normal" Air Force security, RAND's early involvement would likely have been deeper.

The period during which Davies was not formally inducted into codeword compartments was nevertheless very profitably occupied. He was involved with inspection satellites and their role in arms treaties (published mainly some few years later), in early studies of lunar photography, in discussions of why man-in-space was not needed for a reconnaissance role (Davies and Katz, 1958), and in other reconnaissance issues. Included in these pursuits is the first focus on aspects of solar system body imagery which was to become his central NASA program preoccupation.

\footnotetext{
11 The possible benefits of knowledge outside narrow compartments is well-illustrated by the role of Willis Hawkins, a senior Lockheed executive, in remedying a major CORONA problem. The CORONA reentry vehicle had to be spun up for reentry, to maintain vehicle attitude and stability during atmospheric reentry. The spin-up was originally to be done by small solid rockets, which turned out to be prone to failures of various kinds. Hawkins proposed using instead small cold-gas jets, with compressed stored gas, a solution that worked effectively. Hawkins was able to propose this because he was also cleared, among other essentially compartmented activities, for Kelly Johnson's Skunk Works and Lockheed's Polaris program, where analogous usage of cold-gas systems had proved effective. It was often true that individuals inside compartmented programs were rather unaware of activities outside their compartment.
} 
Some of the issues treated in this "difficult" (to use Davies' term) period prior to his CORONA and other compartmental access assumed added significance later. USAF in the 1960s proposed manned satellite or space station reconnaissance systems, adding emphasis to a debate of long standing: Are there resolution limits to satellite imaging systems, and is manned participation capable of affecting any such limitations positively? It was known through both theory and appropriate experiments that seeing through the nonquiescent atmosphere produced limits on resolution. The experiments were varied; one experiment that can be done by the naked eye at night ${ }^{12}$ gives rough estimates for a resolution limit (the astronomer's recent use of adaptive optics is one attempt to avoid such limits). Further, it seemed that, despite the human visual system's integrative powers, no adequately useful improvement on such limits was promised by a human presence on the observing system, so ultimately the notion of manned space recce systems was abandoned as a formal program.

An important subsequent interlude was Davies' role as RAND's liaison/advisor to USAF in Washington, D.C., from 1959 to 1962. Serving the Air Force's intelligence office afforded Davies the opportunity, among a range of activities, for a deep involvement in overhead reconnaissance, including but not limited to the CORONA program (for which he had at last been cleared). His work with CORONA entailed frequent trips to NPIC; NPIC was chiefly responsible for analysis of CORONA photography, and Davies struck up a continuing friendship with Art Lundahl, director of NPIC.

Davies' visits to NPIC were interesting for a number of special reasons. Along with progressive improvements in CORONA's basic camera system, index cameras and stellar cameras were introduced into the CORONA payload to aid the photointerpreter in precisely

\footnotetext{
${ }^{12}$ One experiment is to look at a bright star at night and defocus your eyes so that you see two images of this star simultaneously. You will then typically observe that the brightness of these two star images does not vary in synchronism, and indeed one image will often disappear entirely while the other image remains bright. It will be left to the interested reader to establish how this suggests a rough resolution limit, and what natural measure corresponds to it.
} 
determining the vehicle attitude in orbit. Even more closely related to Davies' later interests was the early introduction of 3-inch focal length mapping cameras into the program (ARGON), whose purpose was to improve then extant datum planes in the Soviet Union (much of this information stemmed from WWII and before acquisitions, and was both inaccurate and incomplete). The ultimate goal was to obtain geodetic locations to much higher accuracy over large areas of the Soviet Union. The new level of accuracy was needed, for example, to precisely locate ballistic missile targets. This mapping program, then undertaken because of certain technical difficulties with achieving precision mapping with the basic high-acuity 24-inch focal length camera, was a limited success. However, the techniques used at NPIC and by others to develop precision photogrammetric products from overhead imagery were clearly an early seed which later grew into Davies' sophisticated and groundbreaking tools for NASA-related mapping programs in which he became the international leader.

The Washington tour also initiated an NRO relationship that lasted throughout the 1960s. The fruits of this relationship were many. Starting as an exemplar with the indifferently successful LANYARD program within CORONA to modify a 66-inch focal length camera originally introduced in the $117 \mathrm{~L}$ readout program to produce hoped-for ground resolutions of the order of 2 feet (a goal not achieved, so the program was quickly cancelled) as an interim system to await the completion of a high-resolution high-acuity system (Richelson, 2003) then under development, ${ }^{13}$ it became very clear that extensive planning was needed to assess capabilities of competing systems, to establish well-founded specifications, to set priorities, to isolate and define critical technical parameters to ensure the best capabilities, and to be able to recommend which systems to select from the array of competing systems. Davies played a central role in such NRO planning exercises until about 1970, and not simply as a

\footnotetext{
13 This system was the KH-7 GAMBIT, first launched on July 12, 1963, and producing about 2-foot resolution, a worthy predecessor to the even better-resolution $\mathrm{KH}-8$ systems that followed. The KH-7 was the subject of at least one preliminary design at Lockheed in 1961.
} 
critic. The fruits of the planning exercises lay in the recommendations on how to improve the articles: reducing light losses, simplifying mechanisms, steps to improve resolution, etc.

For this body of reconnaissance-related work, starting in the early 1950s before the NRO creation and spanning roughly the first decade of NRO functioning, Davies later received a special award from the NRO.

\section{Davies Begins to Switch Careers and Receives a Signal NRO Honor}

During this decade, Davies' carried on many other activities_-acting as an official observer for the implementation of the Antarctic Treaty in 1968 [Figure 1]; discussing Soviet plans and missions such as the ZOND-5 for lunar and planetary exploration; comparing U.S. and Soviet proposals for planetary exploration (Davies and Murray, 1968), prevention of planetary contamination (Murray, Davies, and Eckman, 1967), and a spectrum of space applications; and reviewing issues of inspection by satellites. Some of the relevant planetary exploration documents are coauthored with Bruce Murray (Murray and Davies, 1966). In addition, Davies participated in a number of reviews of the then burgeoning Japanese missile and space programs.

One special, still very highly classified RAND study in which Davies' participated as the 1960s drew to a close was Recce-X, a study that sought to integrate possible future reconnaissance and observation systems with prospective plans for pre-, trans-, and posthostilities phases of various scenarios for nuclear conflict. Naturally, such a study presupposed inter alia an intimate familiarity with future NRO plans and concepts, in which Davies was a key participant.

As Davies himself notes, "By 1970 I retired from the national reconnaissance field." This was certainly not from lack of continuing interest. ${ }^{14}$ One factor was Davies' rising involvement in NASA

\footnotetext{
${ }^{14}$ The subject remained of high interest because by about 1970 technology advances in producing very high definition electro-optical images and exploiting very high bandwidth readouts of those images finally demonstrated as eminently practical the capabilities first visualized for the $117 \mathrm{~L}$ system more than a decade earlier-real-time or near real-time
} 


\section{Figure 1}

Davies and Friend in Antarctica

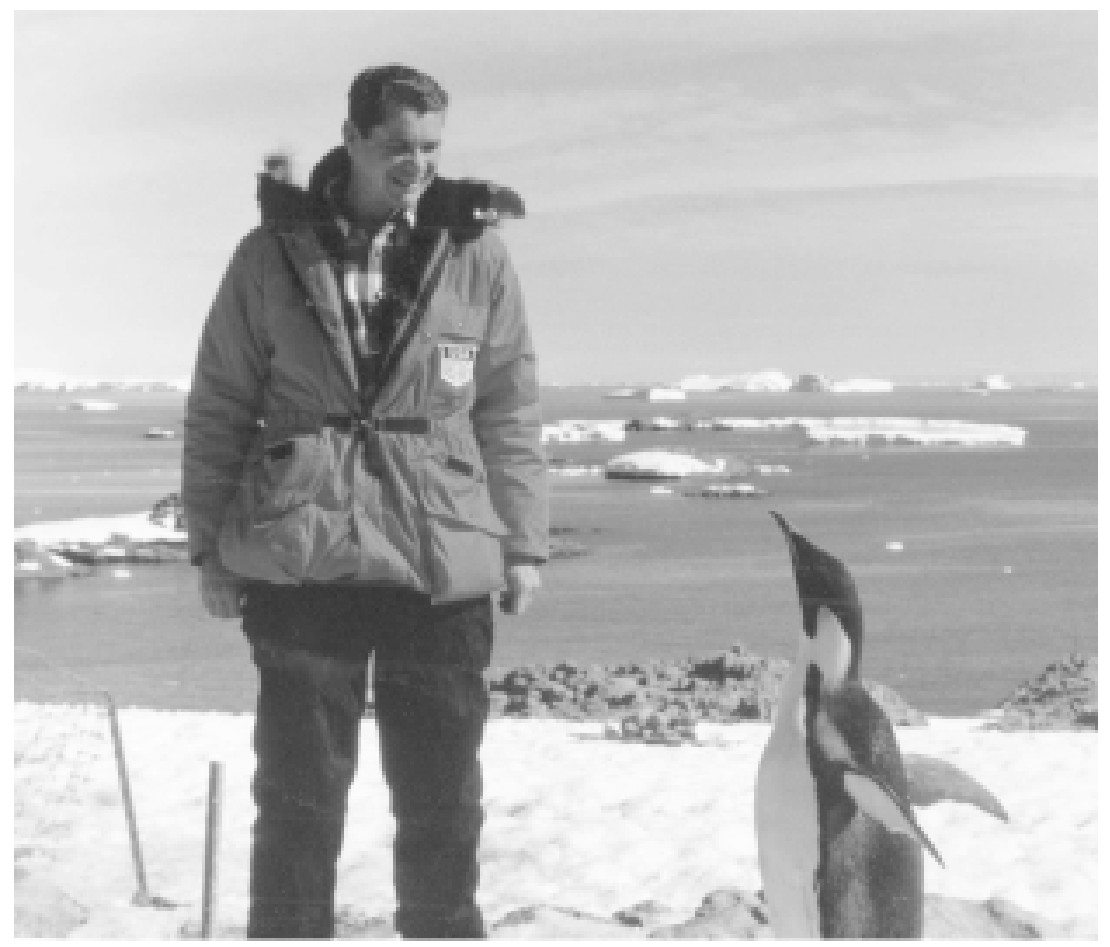

Merton Davies was selected in the 1970 s to be a member of the U.S. delegation in a pioneering international on-site inspection of all the bases in Antarctica to verify treaty compliance to keep that continent free of weapon systems. He relished that opportunity because he believed deeply that such on-site inspections would be essential to ending the Cold War, as indeed proved to be the case in the 1990s.

programs, necessitating overseas travel behind the Iron Curtain. Roughly contemporary were airline hijackings. Both these circumstances gave individuals with high-level clearances some concern, a concern shared by various governmental organizations. RAND, for

transmission of very high resolution reconnaissance imagery. Thus, the needs for physical film recovery essentially vanished, and with it needs for reentry vehicles to deliver data and acceptance of relatively long delays (days or weeks) in getting those data, although film recovery systems persisted for several more years. 
example, was at that time once urged to prohibit more than one person at a time with certain clearances from flying on a given airplane.

By the late sixties, then, Davies was already switching his major interests from DoD-related imagery work to NASA-related imagery efforts, exemplified by such RAND documents as Space Photography and the Exploration of Mars, coauthored with Bruce Murray in 1969. However, one further signal award still lay in the future, recognizing Davies' body of work in classified imagery issues.

On September 27, 2000, Merton Edward Davies was recognized at a ceremony at the NRO Headquarters as a Pioneer Founder of National Reconnaissance, receiving a Founder Award and Citation. The ceremony was attended by the Director of Central Intelligence, George Tenet, and the Director of the National Reconnaissance Office, Keith Hall. For those who have never been involved in these classified imagery issues, especially during critical periods such as the Cold War, 15 it may be difficult to measure the significance of this work, compared with Davies' groundbreaking role in the extensive solar system mapping and cartography initiatives. Let it simply be said that the nature and outcome of the U.S./USSR competition had, as a supremely important determinant, overhead reconnaissance as the sine qua non driver. The Citation summarizes his national reconnaissance career thoroughly:

An engineer, reconnaissance system designer, imagery interpreter, and space cartographer, Mr. Merton Davies participated in all early USAF reconnaissance studies and planning, including the Leghorn-directed Intelligence Development Planning Ob-

\footnotetext{
15 One of the remarkable aspects of the era was how relatively small the community was of individuals whose innovative ideas fueled the technology needs of the time. As just one example, Kelly Johnson's OXCART program crucially needed a precise inlet airflow control technique to allow the aircraft's engines to operate over the entire speed range from zero velocity to design maximum speeds of $M=3.2$. This was done by moving a central conical spike longitudinally within the engine inlet duct to appropriate positions. That such a concept worked, and worked efficiently over a large speed range, was the subject of a patent issued to Robert M. Salter in the mid-1940s - the same Salter so influential later in RAND and Lockheed satellite programs. The success of OXCART as a revolutionary aircraft program relied on this fundamental airflow control concept.
} 
jects. ${ }^{16} \mathrm{He}$ invented the Spin-Pan camera, and collaborated in the film recovery satellite proposal adopted by the USAF that became CORONA. Employed throughout his career at RAND, he continued to serve on NRO and other advisory panels that established reconnaissance requirements and advised on competing reconnaissance systems.

The NRO award was a fitting coda to Davies' illustrious and important career at RAND in many aspects of national reconnaissance. The events involved reflect an era whose environment, at RAND and externally, differed from today's in many subtle degrees and respects. Self-initiated and interdisciplinary research, as Michael Rich has observed, was one central key; actions could flow from ideas without almost interminable delay, quickly on the heels of conception; the basic formulation of innovations of technology and methodology to insert into the mainstream of emerging needs (the what to do) was given at least equal emphasis as the associated analysis guiding us on to what extent (the how much to do) those innovations can/should be pursued (today the classical province of the policy study). Perhaps the lasting hallmarks of the era lay in its acceptance of the notion that the dual considerations of the innovation itself and how best to apply it effectively formed a virtually seamless whole, to effect fundamental and enduring change.

\footnotetext{
16 sic; the word should be "Objectives."
} 


\section{PLANETARY EXPLORATION EMPHASIS (1965-2001)}

\section{A Pioneering Vision for Deep Space Photographic Exploration}

In 1963, planetary exploration was in its infancy. Davies, with his 15 years of experience in the development of satellite observation systems from Earth orbit, grasped better than anyone else at the time that photographic reconnaissance would require good surface maps. Most important, he grasped the central fact that in planetary cartography and geodesy, nothing would be more fundamental than establishing the fiducial point to which all other measurements are related. For a planet, this is the location of the prime meridian-zero longitude-including the exact vector orientation of the spin axis. Upon this foundation of spin axis and surface control points is built the interconnected network of distance, angle, and time coordinates that specify where every feature is and what time it is there. Here on the Earth, contention for "possession" of the prime meridian was a scientific, political, and commercial issue of great moment for centuries, with Greenwich, England, finally prevailing on the world's maps. To have established the prime meridian for a single planet alone could be regarded as a major career achievement by any scientist-an instructive lens through which to view Davies' accomplishments.

In 1963, Davies began a long-term collaboration with Bruce Murray, with the ambitious goal of conducting nothing less than the photoreconnaissance of the entire solar system. Indeed, the dust jacket of their book The View from Space (Davies and Murray, 1971) noted that both were then working on upcoming missions to Mars, Mercury, and Venus and that, in addition,

Both men are currently helping define the objectives and alternative techniques for imaging of the Outer Planets and their principal satellites. Thus both find themselves in the extraordinary circumstance of simultaneously working on picture taking 
spacecraft to all the major planets and major satellites in this Solar System.

Davies was able to fulfill that dream, except for Pluto, which was not to be explored in his lifetime. No one else in the world shares that distinction. Davies became a key team member of ten planetary missions: Mariners 6, 7, and 9, and Mars Global Surveyor to Mars; Mariner 10 to Venus and Mercury; Voyagers 1 and 2 to Jupiter, Saturn, Uranus, and Neptune; Clementine to the moon; Galileo to Jupiter; and Magellan to Venus.

His key contribution was to develop novel techniques and hardware that enabled NASA deep-space imaging systems to acquire useful mapping and geodesy data. This involved extending his USAF/RAND background in high-resolution aerial and balloon film imaging to three novel and very different space-based digital sensors: (1) slow-scan vidicons, (2) charge-coupled devices (CCDs), and (3) synthetic aperture radar (SAR).

These fundamental contributions to planetary mapping in turn led to long service on the International Astronomical Union committees that name the surface features of Mercury, Venus, Mars, and the satellites of Jupiter, Saturn, Uranus, and Neptune.

\section{Revolutionary Technical Steps Required to Advance from Earth-Orbital to Planetary Spacecraft Imaging}

It is not widely recognized just how challenging is mapping and geodesy from planetary spacecraft. As highlighted earlier in this paper, CORONA required great innovations in adapting the camera system to the spacecraft environment and orbital motion, and in developing the capsule recovery process, but the film sensor itself drew upon many decades of aerial and balloon experience. However, film recovery was obviously not feasible from planetary distances. Accordingly, Jet Propulsion Laboratory (JPL) had to fashion a radical new electronic digital approach to space imaging. Indeed, the planetary challenge brought home especially how uniquely film recovery for CORONA provided such a superb combination of high-resolution sensor and of unsurpassed data-storage capacity. 
Electronic alternatives were developed, but they were exceedingly limited in capability and capacity in comparison to even the earliest CORONA capability. Electronic communication rates were extremely low initially; Mariner 4 in 1965, the first successful Mars probe, returned data at $8 \mathrm{bits} / \mathrm{sec}$. It was easily relayed from the Deep Space Network (DSN) station at Goldstone, California, to JPL by teletype! Furthermore, electromechanical tape recorders in the space environment were unreliable then (and are still) and of very limited capacity; Mariner 4's tape recorder had an effective capacity of only about $10^{6}$ bits, within which all 21 tiny framelets were recorded. This is very roughly one-tenth the information content of an ordinary 35$\mathrm{mm}$ camera frame! [Figure 2]

\section{Figure 2}

Mariner 4 in 1965 Discovers a Lunar-Like Mars

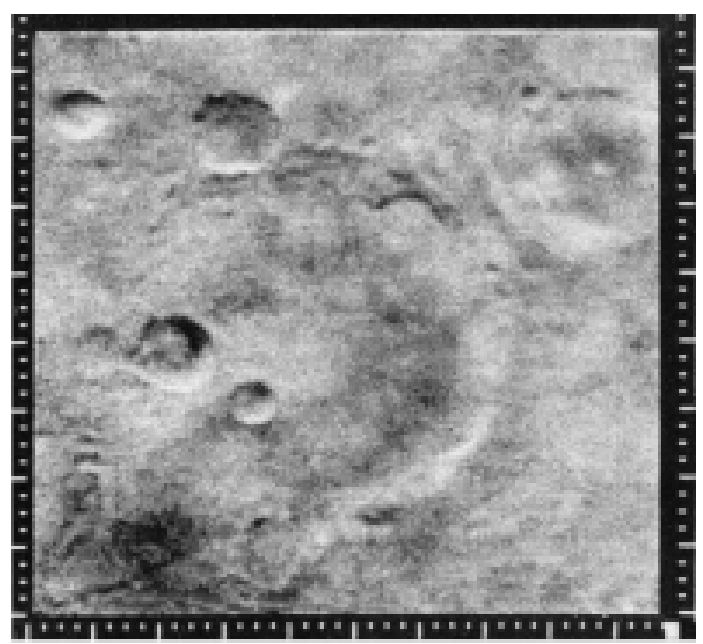

The first successful Mars probe had a launch mass of only $\mathbf{5 7 5}$ pounds because the small Atlas/Agena was the only available U.S. launch vehicle at the time. Hence, it carried a very small, primitive digital TV camera that returned only a handful of useful images limited to 6-bit encoding. Nevertheless, those first $200 \times 200$ pixel images revealed an unexpectedly heavily cratered surface much more like the Moon than the Earth, contrary to popular and scientific expectations. 
Planetary communication capacity grew an extraordinary $10,000-15,000$-fold over the subsequent two decades, and onboard electronic storage increased by a factor of 1,000 or so. Nevertheless, it was not until the Mars Global Surveyor mission, starting in the late 1990s, that imaging surface resolution and total data return could be argued to be adequate for satellite exploration of an alien surface. Perhaps by then planetary exploration had developed into something comparable to the earliest CORONA capability four decades earlier.

How to provide for planetary spacecraft imaging? JPL's approach in the mid-1960s was to invent the slow-scan digital vidicon camera system. This pioneering endeavor apparently was the first digital imaging system for any application in the world. These digital camera systems were subsequently continually improved and enabled the orbital imaging for all the Mariner and Viking missions to Mars, the Mariner mission to Mercury, and for the Voyager missions to the Outer Planets.

The slow-scan feature was uniquely necessary to provide temporary buffer storage while the vidicon sensor was read out. Otherwise, the tape recorder couldn't handle even the minimum output bandwidth of the vidicon. A 42-second storage time of the image on the vidicon was achieved, long enough for the 40,000 6-bit pixels in a single Mariner 4 image to be read out into the tape recorder. These primitive slow-scan digital vidicons produced images that revolutionized our understanding of Mars' surface, but were poorly suited to mapping and geometric measurements because they necessarily used electromagnetic focusing and scanning of the vidicon "Read" beam [Figure 3].

Thus, they were intrinsically nonuniform across the focal plane, and as well were quite temperature sensitive and suffered from a variety of other special problems as to be expected from such a specialized and novel development. The cameras used for the 1969 Mars flybys, Mariners 6 and 7, which was Davies' first planetary mission, suffered from the same general limitations but incorporated important improvements in degree of encoding, optical resolution, and total data return [Figures 3 and 4 ]. 


\section{Figure 3}

Mariner 6/7 Instrument Platform

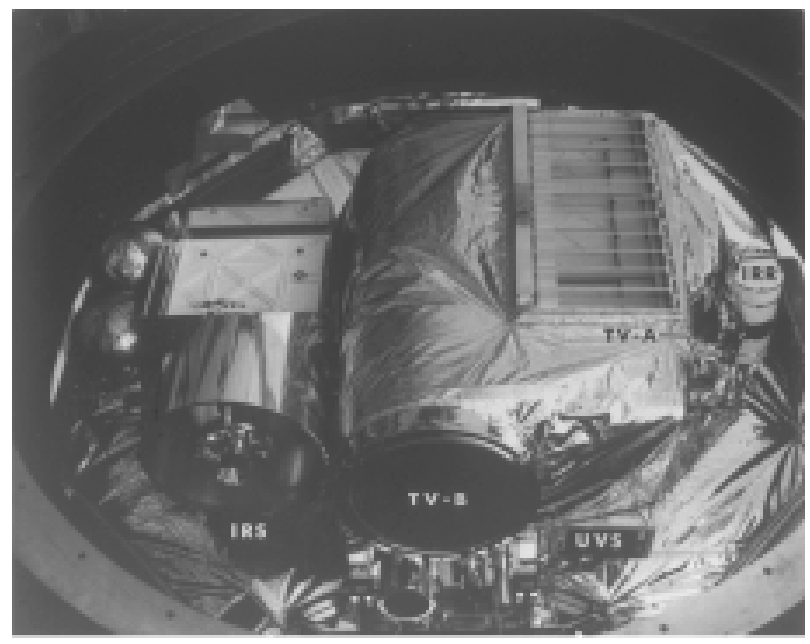

Even with the greater launch mass margin afforded by the Atlas Centaur vehicle, the Mariner 6 and 7 instrument platform was a difficult thermal environment for the 500 $\mathrm{mm}$ focal length optics of the high-resolution TV camera (TV B). That thermal issue became critical subsequently in order to exploit the rare opportunity to launch the first mission to Mercury and its hot environment in 1973 by adapting a single Mariner 6/7-type spacecraft with "minimal" changes. The flyby geometry at Mercury (nighttime closest approach) required trebling the focal length within essentially the same external size of the camera barrel. In addition, a second, twin high-resolution TV camera was added, both now located on a scan platform. The wide-angle camera (TV A) was dropped for the Mercury mission as were the Infrared Spectrometer (IRS) and the Ultraviolet Spectrometer (UVS). A small Solar UV Occulation spectrometer and four particles and field instruments were also added. 


\section{Figure 4}

Mariner 6/7 Digital Vidicon Cameras

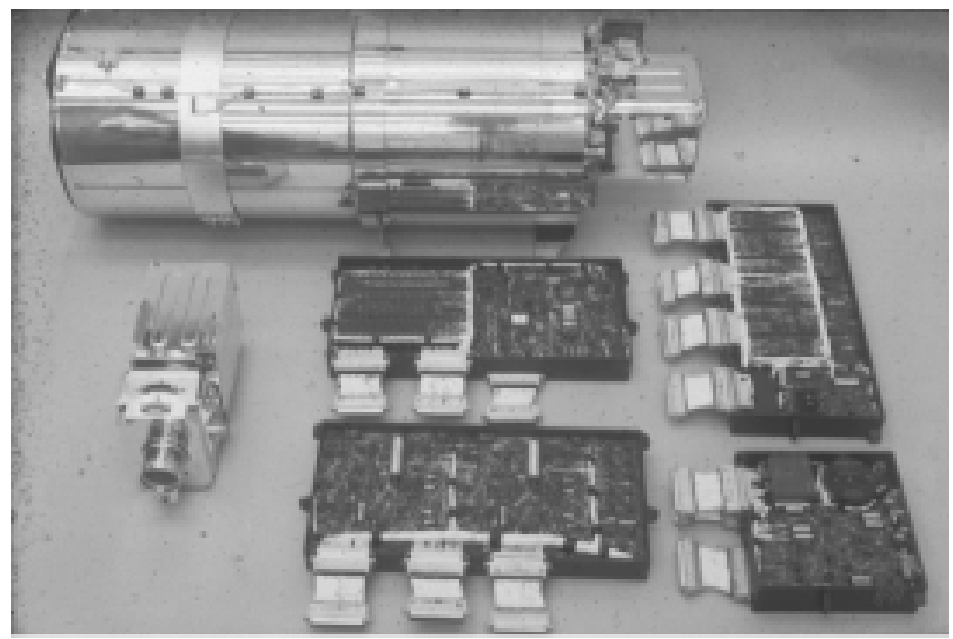

The sensor assembly that incorporated the slow-scan vidicon, the filters, and the mechanical shutter can be seen attached to the focal plane of each optical system. A heater band is evident near the front of the high-resolution telescope barrel. Adjacent in the scene are the ponderous mid-1960s digital electronics required to operate the camera and read it out.

\section{The Innovations Introduced by Davies to Make Deep Space}

\section{Electronic Imaging Systems Capable of Precise Mapping of Mars}

Davies, undismayed by these practically insurmountable problems for mapping, worked successfully with the JPL camera team to develop suitable geometric calibration correction procedures. This involved permanently locating precisely positioned reseau points on the glass surfaces forming the focal planes of each vidicon tube and precisely measuring the apparent position in pixel coordinates of test targets through temperature and intensity variations and other controls. (The magnitude of the necessary geometric corrections can be judged by the image edge distortions in Figures 5 and 6.) Then, the digitally corrected pixel fields based upon inflight temperature estimates and 
Figure 5

Mariner 6 Confirms Cratered Surface

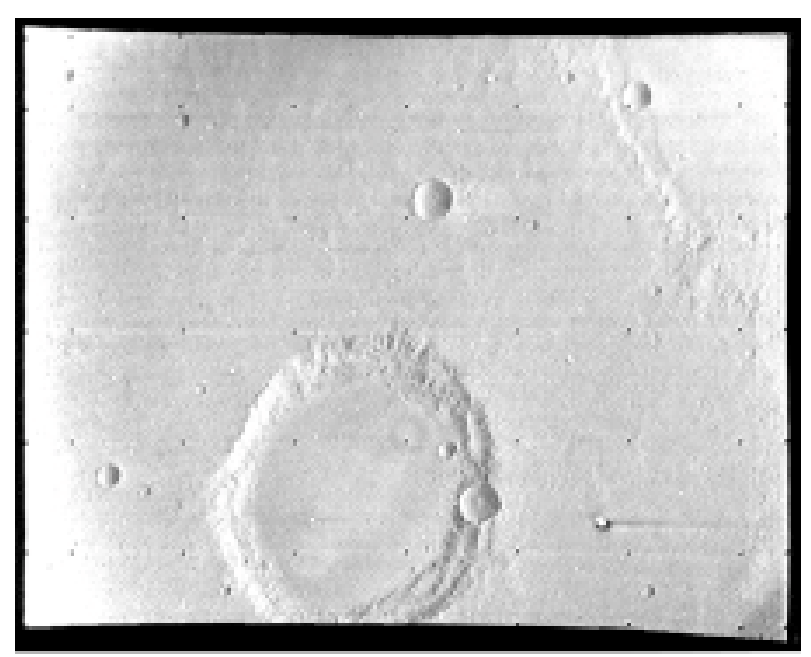

Some of the better close-up images returned from Mariner 6 in August 1969 reinforced the surprisingly lunar-like appearance of Mars from Mariner 4 in 1965, although clues to other uniquely Martian surface features were also present (and which were strikingly amplified in images returned by the orbiter Mariner 9 in 1971-72). This highly processed version of Frame 6N18 (and Figure 6) displays, however, some of the many defects of these first-generation digital images when applied to more quantitative work. The bright band along the left-hand side is saturation where the first-generation high-pass digital filtering overresponded to the black-tolight edge along the left side (the side from which the line-by-line filtering began). The white "tails" to the right of each dark reseau point resulted from the same primitive high-pass filtering technique used. Faint "doughnuts," especially in 6N18, are the result of out-of-focus dust particles located on the glass plate covering the vidicon surface. The dark bands curving vertically on $7 \mathrm{~N} 11$ are second- and third-generation aftereffects from inadequately removed residual image from earlier exposures when the high-contrast limb of the planet was imaged.

Most serious for Davies' geometric measurements were the extreme geometric distortions evident in these calibrated images by the prominent curving of the edges of the scenes. This geometric distortion was temperature dependent, among other things, and thus exact calibration required matching the sparse preflight bench test data to the actual inflight vidicon temperatures, which could only be reconstructed approximately. 


\section{Figure 6}

Mariner 7 Explores the Edge of the Martian Seasonal Cap

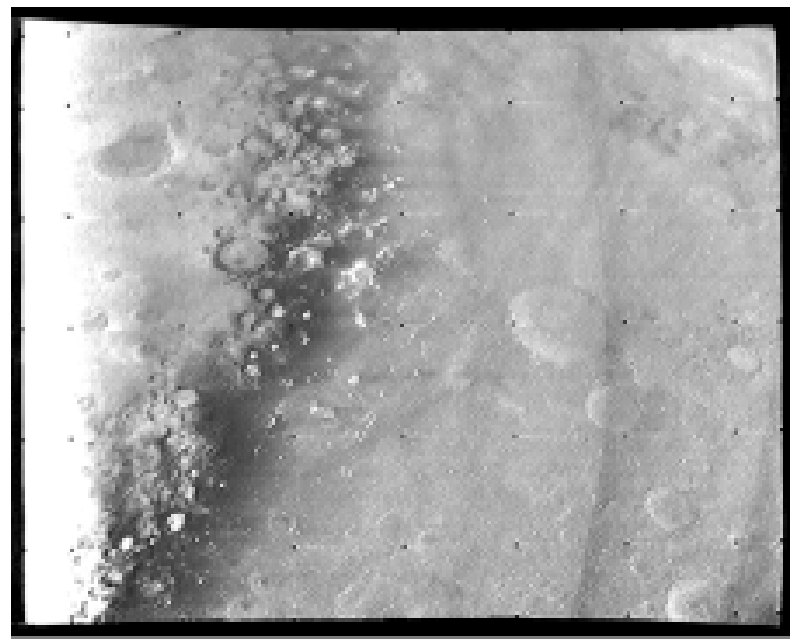

Mariner 7 was tasked with confirming or rejecting the surprising implication of Mariner 4's discovery in 1965 that the surface pressure of Mars' atmosphere was far lower than expected-so low, in fact, that $\mathrm{CO}_{2}$ frost and not water ice should compose the white polar covering which appeared and disappeared each winter. TV images like this one supported the bore-sighted infrared spectrometer and infrared radiometer in successfully identifying pure $\mathrm{CO}_{2}$ frost on the surface, and ruling out water frost as the component of the seasonal white frost.

intensity levels were applied to actual Mars images, enabling a fair reconstruction of the severe geometric distortions present.

Next, Davies and a series of RAND collaborators carefully measured the pixel coordinates of distinct features within that image. Then, using the precise time of acquisition and a Mars ephemeris, he projected them onto a provisional Mars surface coordinate system based upon the approximately correct camera location and orientation calculated from the available spacecraft tracking and pointing data. Fortunately, Mariners 6 and 7 had obtained a good set of approach images of Mars [Figure 7], which provided a way for them to 
Figure 7

Mariner 7 Surveys the Globe of Mars on Approach
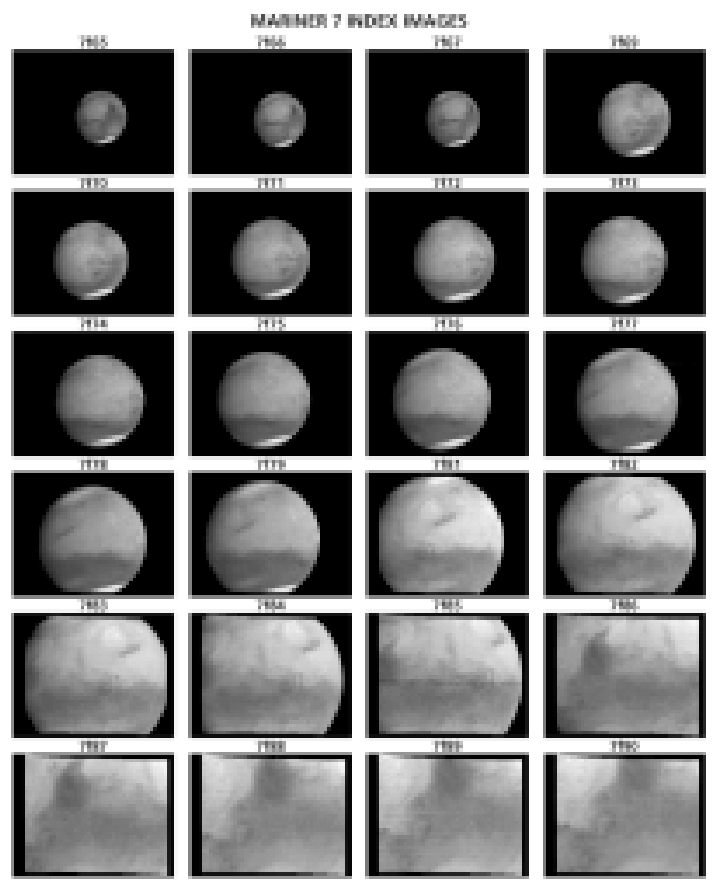

Mars features can be recognized moving from left to right in succeeding frames as Mariner 7 approached the planet. This was higher-resolution global coverage of Mars than ever acquired before and provided the basis for Davies to tie together $\mathbf{1 1 2}$ specific control points he defined in close approach frames, as illustrated in Figures 5 and 6.

connect uniformly the 112 measured and corrected points recognized and designated as control points in individual close-up pictures. This entire process was iterated repeatedly to minimize errors and to provide corrections to the spacecraft pointing data.

Davies thus created the first Mars control net (Davies and Berg, 1971), which became the standard template for the extensive global mapping and Mars cartography generated by the Mariner 9 Orbiter, 1971-72, and the Viking Orbiters, 1976-79. The position and orientation of the rotational pole of Mars were also improved in this way, 
enhanced by the long-term orbital coverage of Mariner 9 and Vikings 1 and 2. Then, the precise long-term radio tracking of the position of the Viking landers fixed to the Martian surface added an important complementary way to further improve knowledge of the pole and rotation rate. Additional improvements resulted from similar radiotracking techniques with the Pathfinder Mars Lander in 1997.

However, every planetary coordinate system, including Earth's at Greenwich, England, requires a tie to the actual surface of the rotating planet. The prime meridian is defined by that location and the spin vector of the planet. Previous Earth-based telescope observers of Mars had chosen a very large conspicuous dark feature, Sinus Meridiani, which was adequate for the very low resolution mapping of albedo features possible through a telescope. Davies recognized that a new, small easy-to-locate topographic feature (not a vaguely defined and possibly variable albedo feature) was needed now to connect the Mars latitude and longitude system to the actual Martian surface at increasingly high resolution. He settled on a small, simple crater located near the center of a large, conspicuous crater within Sinus Meridiani. The large crater was christened "Airy" in honor of the pioneer of the Greenwich longitude measurement system, and the small crater became "Airy 0" [Figure 8]. Airy 0 defines the prime meridian for Mars. Because its actual surface position is relocated more precisely in succeeding decades, Mars' longitude system will be shifted ever so slightly for 0 longitude to continue to pass exactly through the center of Airy 0 (Davies and Arthur, 1973; de Vaucouleurs, Davies, and Sturms, Jr., 1973; and Davies, 1973).

The Mars Global Surveyor mission beginning in 1999 added the very high resolution Mars Orbiter Camera (MOC) imaging to sharpen the Mars control net further. (Davies was also a member of the MOC camera team and contributed to design concepts of this extraordinarily successful high-resolution camera, achieving a 3.5meter focal length and best surface resolution of a few meters.) Most important, the nadir-pointing laser altimetry experiment (MOLA) 


\section{Figure 8}

The Fundamental Reference Point for Mars, Airy 0
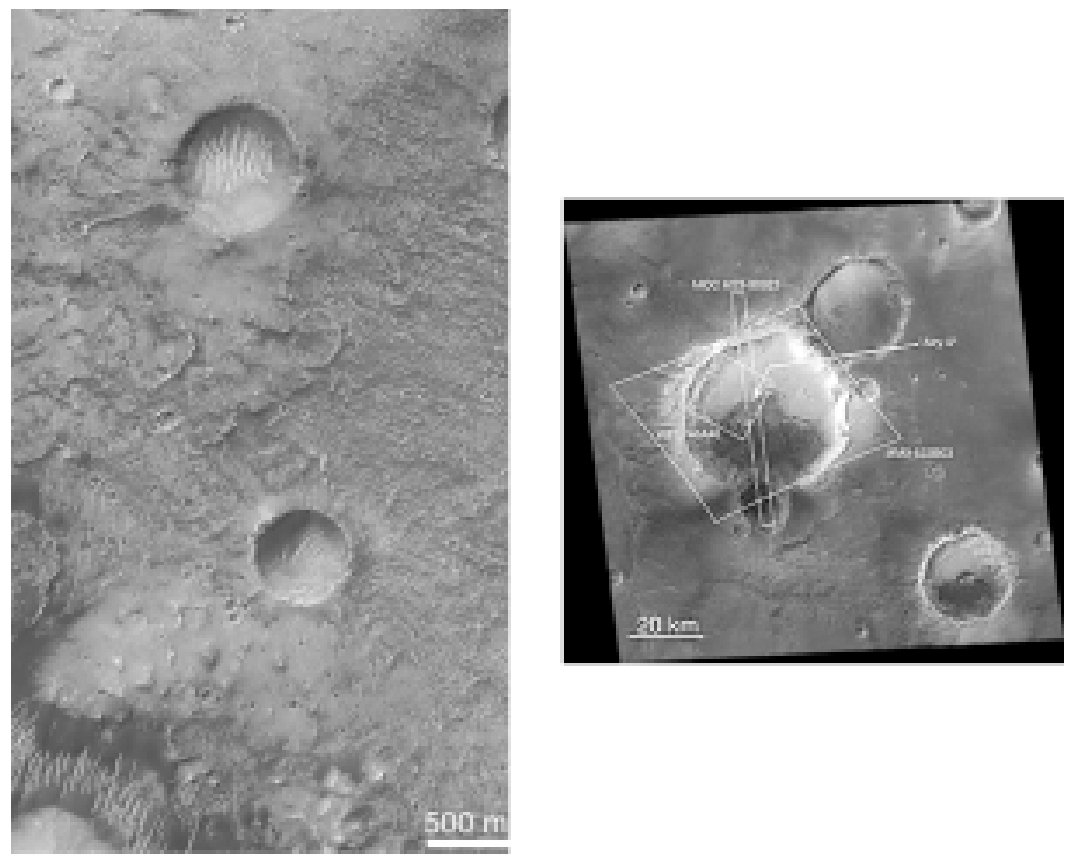

By analogy with Greenwich, England, Davies and colleagues designated a welldefined one-kilometer (diameter) crater shown in the vertical image here as the permanent surface location, defining the prime meridian for Mars. Airy $\mathbf{0}$ in turn is near the center of a larger, conspicuous crater (shown here in the smaller, equal dimensional image) designated "Airy Crater" located near the center of a very large dark region adopted by telescopic astronomers as their early reference point and thus named "Sinus Meridiani." The conspicuous light, parallel bands on the floors of Airy 0 and of several nearby craters are sand dune fields.

The extraordinary increase in image resolution between the primitive slow scan vidicon on Mariner 4 in Figure 2 (about 3 kilometers) and the CCD narrow-angle camera on the Mars Global Surveyor orbiting spacecraft in Figure 8 (about 3 meters) illustrated in the image of Airy 0 above is an appropriate testament of the three and a half decades of improvement in U.S. planetary space camera development. 
aboard the spacecraft successfully accumulated many tens of millions of precisely located height points, so that by 2001-2002 a remarkably precise three-dimensional Mars surface could be created from them. Concurrently, the gravity field of Mars was inferred to unprecedented precision from the same tracking. Hence, the MOLA net provides precise height information, combined with relatively complete gravity data, thus defining the Martian geoid also at unusually high precision. Using a common tie at Airy 0, Davies' Mars control net is being assimilated into a precise three-dimensional Mars coordinate system, providing better height and positional control globally there than is generally available on Earth.

This remarkable three-dimensional surface coordinate system together with the accurate new geoid system will enable far more precise and safer robotic surface operations on Mars than would have been the case if Davies had not pioneered and sustained ever more precise surface coordinate systems for the Red Planet. Davies' handiwork will stretch well into the 21 st century, possibly even supporting initial human surface operations there.

\section{Important Scientific Results at the Moon, Mercury, and Venus Enabled by Davies' Techniques and Optical Design Contributions}

An unusually favorable alignment of Earth, Venus, and Mercury created the opportunity for an early flyby of planet Mercury by launching a Mariner Mars 6/7 class mission toward Venus in 1973 and exploiting the gravity swingby of a close passage of Venus to reach Mercury in 1974. NASA decided to pursue that opportunity, but only on a financially constrained basis. A single Atlas Centaur launch vehicle would launch a single Mariner 6/7-type spacecraft with minimum changes. Bruce Murray was selected to lead the imaging team for this mission and Davies was again chosen for the mapping responsibilities.

A major new scientific requirement was added to the Mercury mission-to search for a magnetic field. This required adding a magnetometer and boom, but most seriously for imaging, it necessitated also passing close by the NIGHT side of the planet! The test for a magnetic field necessitated searching for characteristic disturbances to 
the solar wind caused by the obstruction to its outward flow from the sun by the presence of the planet.

Davies led an intense search for an affordable way to modify the slow-scan vidicon and 500-mm focal length telescope combination of Mariners 6 and 7 (and by then also that used by the Mariner 9 Mars orbiter). The design team came up with an attractive, but risky, solution: Treble the focal length of the Mariner 6/7 design and use twin camera systems on alternate 42 -second readout cycles. This way, many high-resolution images under good low lighting could be captured well before and well after passing the darkened surface at closest approach. In addition, the TV team was able to persuade the telemetry engineers at JPL that television images can be quite interpretable even with considerable "salt and pepper" telemetry noise. Hence, the communication bandwidth for Mariner 10 could be increased greatly within existing power and antenna capabilities by accepting a much higher noise level. This meant that in addition to acquiring a full tape recorder, as had the earlier Mars Mariners, Mariner 10 could also transmit the 115,000-bps output video signal directly to Earth during many intervals. As a consequence, Mariner 10 would return many thousands of extraordinarily sharp images of Mercury, rather than the few hundred lower-resolution frames that otherwise would have been the case.

Trebling the focal length of an existing optical design is never easy, but in this case the team was constrained as well for volume and configuration reasons to keep the rather short overall length (550 $\mathrm{mm}$ ) of the Mariner 6/7 telescope nearly the same for Mariner 10 (see Figure 3). Thus, the increase in focal length from 500 to $1500 \mathrm{~mm}$ had to be accomplished entirely by secondary mirror magnification at the front of the telescope, where there would maximum vulnerability to thermal gradients.

Davies' experience with development of high-performance optical systems for the DoD coupled with his friendly style greatly helped JPL and its contractors as they struggled with the challenge of building one of the highest-resolution space cameras ever developed by NASA at that time. That leadership in camera system design and implementation paid off extraordinarily when Mariner 10 finally 
reached Mercury, returning many thousands of images of its previously unknown surface down to $\sim 100$ meters resolution.

Davies efficiently and quickly applied the control point techniques perfected at Mars to selected Mercury images to produce the first control net for that planet, the basis of subsequent maps of the approximately 40 percent of the surface that Mariner 10 usefully imaged (Davies, 1975). He established the analogue of Greenwich and Airy 0 as the small crater Hun Kal through which the 20 degree West Longitude is defined to pass. He also helped produce the beautiful NASA Atlas of Mercury (Davies et al., 1978).

Mercury has not been visited by another spacecraft since Mariner 10, but new information about the pole location came from an unexpected source. Powerful ground-based radars and receivers discovered bright ice deposits in permanently shaded polar craters there in 1991. These clear reflections, when compared with Davies' Mariner 10 control points, permitted a correction to Mercury's spin axis and hence a revision to the Mercurian coordinate system (Robinson et al., 1999).

\section{On to the Outer Solar System}

While the Mariner 10 team was implementing their unprecedented high-resolution planetary camera, the early development of the grandest exploration of the 20th century was starting up at JPL. The Voyager mission, targeted to launch in 1977, aimed to explore Jupiter (1979), Saturn (1980), Uranus (1986), Neptune (1989), and their many moons. This mission would pose all the imaging challenges of Mariner 10 plus the major additional challenge of having to image drastically fainter objects than Mercury as the spacecraft traveled outward from the sun, ultimately to a distance 100 times further from the sun than Mercury. The intensity of sunlight falling on those surfaces would be up to 10,000 times fainter than at Mercury.

Nevertheless, the Mariner 10 slow-scan vidicon combined with the 1500-mm focal length design was selected and Davies and several others from the Mariner 10 team were incorporated into the early Voyager camera team. The long exposures and potential image smear problems were overcome by (1) extending substantially the slow-scan 
vidicon exposure range, (2) introducing spacecraft techniques to ensure especially stable spacecraft attitude during image taking, and (3) developing programmable scan platform motion to compensate precisely for spacecraft trajectory motion at the longest exposures.

As a consequence, all the giant planets and their principal moons, the rings of Saturn, and many dozens of smaller moons were imaged by Voyagers 1 and 2 over their 12-year journey of exploration. An incredible scientific harvest indeed for science and for the public. Davies accomplished his objectives of establishing control nets for not only the large Galilean Moons of Jupiter but for nearly all of the significant moons orbiting Saturn and Uranus, and even Neptune's moon Triton, at the very edge of the domain of planets (Davies, Rogers, and Colvin, 1991). During the 1990s, Voyager's legacy was further augmented by the rich new data sets returned by the Galileo Orbiter mission for Jupiter, in which Davies also participated. In addition to establishing the basic control nets for the four Galilean moons, he enabled important measurements of the shape of Jupiter's volcanic moon Io (Thomas et al., 1998) as well as helping develop evidence for a subsurface ocean on its neighboring moon Europa (Carr et al., 1998). Such hints of subsurface water there have led to Europa becoming a principal long-term target in the NASA search for life elsewhere in this solar system. Galileo also provided the opportunity for Davies and his colleagues to image the asteroid Ida and its unsuspected small companion, Dactyl, and to learn about their orbital behavior (Davies et al., 1996; Thomas et al., 1996; Belton et al., 1996; Veverka et al., 1996). The asteroid Gaspra also was targeted by Galileo's trajectory, providing additional discovery opportunities (Davies et al., 1994).

Davies' careful and conservative approach to establishing control nets and inferring pole positions paid off in an unexpected way with Hyperion, a moon of Saturn. In trying to compile the data for an early Voyager team report, he couldn't get the data to converge to the degree he expected. Rather than simply choosing some kind of average values, he stated the rotational pole to be "indeterminate." Later, a specialist in orbital dynamics determined that indeed it was not in the usual rotational state for such moons, but was instead in a 
"chaotic rotational state" due to the unusual gravitational influence of the large moon Titan on it. This revealed yet another of the many, many delicate gravitational interactions Voyager discovered in investigating the systems of rings and moons around each of the four Giant Planets.

During the 1990s, Davies also was able to extend the control point approach to the surface of Venus as imaged by SAR on the Magellan mission (Davies et al., 1992). In addition, improved data on the spin of the moon were acquired over many years following the Apollo landing through continued laser illumination from Earth of small retroreflectors originally emplaced by the Apollo astronauts. Through decades of careful observations, improved vector information about the lunar spin axis became available. One of the last papers Davies published was concerned with using that new data to improve the lunar control nets he and others had built up from Clementine, Galileo, and even Mariner 10 imaging observations over the preceding decades (Davies and Colvin, 2000).

Davies remarkable achievements at the forefront of planetary exploration were acknowledged in 1999 by his election as a Fellow of the American Geophysical Union for outstanding contributions to both planetary science and geodesy. The citation read, in part,

Starting in the mid 1960s Davies shifted from the front lines of the Cold War to the front lines of civil planetary exploration. $\mathrm{He}$ advocated and ingeniously applied spacecraft imaging to measure the topography, shapes and rotational properties of moons and planets....

Rarely, has one pioneering scientist been able to apply his novel techniques so widely and successfully. No one else has had more impact on the quantitative basis for map making, on the definition of international conventions of Coordinates and Rotational Elements, on the basis for Solar System Nomenclature. Davies' legacy to the exploration of this Solar System will reach far into the future, just as did the contributions of the early map makers and geodesists of our own continent. 


\section{CONCLUSIONS}

Past histories of RAND and its role in the Cold War have emphasized its contributions to critical weapons technologies (e.g., the ICBM) and to its pioneering efforts in strategic thinking and tools for conflict analysis (e.g., the Wohlstetter-led basing study). A good summary of this role is Hounshell (1998). Fields such as reconnaissance have been held secondary, providing support for weapons and strategies. Perhaps it is now time to also emphasize these "secondary" influences, and to note especially the contributions of individuals like Mert Davies.

Davies' long professional career closely paralleled the threats to and opportunities for the United States created by post-World War II space technology. He was a pioneer in the development of highly secret Cold War satellite reconnaissance systems, and then displayed unusual personal versatility in switching careers to catch the emerging opportunities for exploring the planets, including Voyager's sublime journey to the very edge of our solar system. RAND provided the working environment for this creative and innovative individual for 55 years to the great benefit of both.

Davies remained productive to very end of his life, reflecting through his achievements some of the extraordinary times in which he lived.

What a ride! 


\section{REFERENCES CITED (in order of citation)}

Augenstein, B. W., Roles and Impacts of RAND in the Pre-Apollo Space Program of the United States, IAA-95-IAA.2.1.05, International Astronautical Conference, 1995.

Augenstein, B. W., R. G. Wilson, et al., Long-Range Surface-to-Surface Ramjet Missiles: Preliminary Investigations and Results, Santa Monica, Calif.: Project RAND, RA-15070, March 1, 1948.

Davies, M. E., C. R. Culp, and T. F. Higgins, Long-Range Surface-toSurface Rocket and Ramjet Missiles: Structure and Weights, Santa Monica, Calif.: R-182, May 1, 1950.

Miller, J., The X-Planes, New York: Crown Publishers, 1988.

Lipp, J. E., and R. M. Salter, eds., Project Feed-Back, Summary Report (2 volumes), Santa Monica, Calif.: RAND, R-262, March 1, 1954.

Augenstein, B. W., "A Revised Development Program for Ballistic Missiles of Intercontinental Range," Santa Monica, Calif.: RAND, Special Memorandum No. 21, February 8, 1954.

Davies, M. E., The FEED-BACK Simulation Pictures Taken at RCA, Santa Monica, Calif.: RAND, RM-1555-PR, September 16, 1955.

Davies, M. E., A. H. Katz, et al., A Family of Recoverable Reconnaissance Satellites, Santa Monica, Calif.: RAND, RM-2012, November 12, 1957.

Greer, K. E., "CORONA," CIA Studies in Intelligence, Supplement 17, Spring 1973.

McDonald, R. A., "CORONA: Success for Space Reconnaissance, a Look into the Cold War, and a Revolution for Intelligence," Photogrammetric Engineering and Remote Sensing, June 1995.

Day, D. A., J. M. Logsdon, and B. Latell, eds., Eye in the Sky: The Story of the CORONA Spy Satellites, Washington, D.C.: Smithsonian Institution Press, 1998.

Taubman, P., Secret Empire-Eisenhower, the CIA, and the Hidden Story of America's Space Espionage, New York: Simon and Schuster, 2003.

CIA 1977 Intelligence Monograph, Critique of the Codeword Compartment in the CIA, Center for the Study of Intelligence, TR/1M77-02J, TCS 4530-77, March 1977.

Davies, M. E., and A. H. Katz, "A Dim View of the Man in Space, or, We Don't Need Him for RECCE,” Internal Note, Santa Monica, Calif.: RAND, January 13, 1958. 
Richelson, J. T., "A 'Rifle' in Space: USAF's KH-7 Spy Satellite System Constituted a Major Advance in Overhead Intelligence Collection," Air Force Magazine, Vol. 8b, No. 6, June 2003.

Murray, B. C., and M. E. Davies, A Comparison of U.S. and Soviet Efforts to Explore Mars, Santa Monica, Calif.: RAND, P-3285, January 1966. Also published in Science, Vol. 151, 1966.

Davies, M. E., and B. Murray, The Soviet Union's Zond 5: Is It Also a Planetary Spacecraft? Science, Vol. 162, pp. 245-246, 1968.

Murray, B. C., M. E. Davies, and P. K. Eckman, Planetary Contamination II. Soviet and U.S. Practices and Policies, Science, Vol. 155, pp. 1505-1511, 1967.

Davis, M. E., and B. C. Murray, The View from Space, New York and London: Columbia University Press, 1971.

Davies, M. E., and R. A. Berg, "Preliminary Control Net of Mars," Journal of Geophysical Research, Vol. 76, No. 2, pps. 373-393, January 10, 1971.

Davies, M. E., and D.W.G. Arthur, "Martian Surface Coordinates," "The Mariner 9 Areographic Coordinate System," Journal of Geophysical Research, Vol. 78, No. 20, pp. 4355-4394, July 10, 1973.

De Vaucouleurs, M. E. Davies, and F. M. Sturms, Jr., "The Mariner 9 Areographic Coordinate System," Journal of Geophysical Research, Vol. 78, No. 20, pp. 4395-4404, July 10, 1973.

Davies, M. E., "Mariner 9: Primary Control Net," Photogrammetric Engineering, Vol. 39, No. 12, December 1973, pp. 1297-1302.

Davies, M. E., "Surface Coordinates and Cartography of Mercury," Journal of Geophysical Research, Vol. 80, No. 17, June 10, 1975.

Davies, M. E., S. E. Dwornik, D. E. Gault, and R. G. Strom, NASA Atlas of Mercury, NASA Scientific and Technical Information Office, 1978.

Robinson, M. S., M. E. Davies, T. R. Colvin, and K. Edwards, "A Revised Control Net for Mercury," Journal of Geophysical Research, Vol. 104, E12, pp. 30,847-30,852, 1999.

Davies, M. E., P. G. Rogers, and T. R. Colvin, "A Control Network of Triton," Journal of Geophysical Research, Vol. 96, E1, pp. 15,675-15,681, 1991.

Thomas, P. C., M. E. Davies, T. R. Colvin, J. Oberst, P. Schuster, G. Neukum, M. H. Carr, A. McEwen, G. Schubert, M.J.S. Belton, and the Galileo Imaging Team, "The Shape of Io from Galileo Limb Measurements," Icarus, 1998. 
Carr, M. H., et al., "Evidence for a Subsurface Ocean on Europa" Nature, Vol. 391, pp. 363-365, 1998.

Davies, M. E., T. R. Colvin, M.J.S. Belton, J. Veverka, and P. C. Thomas, "The Direction of the North Pole and the Control Network of Asteroid 243 Ida," Icarus, Vol. 120, pp. 33-37, 1996.

Thomas, P. C., M.J.S. Belton, B. Carcich, C.R. Chapman, M.E. Davies, R. Sullivan, and J. Veverka, "The Shape of Ida," Icarus, Vol. 120, pp. 20-32, 1996.

Belton, M.J.S., B.E.A. Mueller, L. A. D’Amario, D. V. Byrnes, K. P. Klaasen, S. Synnott, H. Breneman, T. V. Johnson, P. C. Thomas, J. Veverka, A. P. Harch, M. E. Davies, W. J. Merline, C. R. Chapman, D. Davis, T. Denk, G. Neukum, J.-M. Petit, R. Greenberg, A. Storrs, and B. Zellner, "The Discovery and Orbit of 1993 (243)1 Dactyl," Icarus, Vol. 120, pp. 185-199, 1996.

Veverka, J., P. C. Thomas, P. Helfenstein, P. Lee, A. Harch, S. Calvo, C. Chapman, M.J.S. Belton, K. Klaasen, T. V. Johnson, and M. Davies, "Dactyl: Galileo Observations of Ida's Satellite," Icarus, Vol. 120, pp. 200-211, 1996.

Davies, M. E., T. R. Colvin, M.J.S. Belton, J. Veverka, and P. C. Thomas, "The Direction of the North Pole and the Control Network of Asteroid 951 Gaspra," Icarus, Vol. 107, pp. 18-22, 1994.

Davies, M. E., T. R. Colvin, P. G. Rogers, P. G. Chodas, W. L. Sjogren, W. L. Akim, E. L. Stepanyantz, Z. P. Vlasova, and A. I. Zakharov, "The Rotation Period, Direction of the North Pole, and Geodetic Control Network of Venus," Journal of Geophysical Research, Vol. 97, E8, pp. 13,141-13,151, 1992.

Davies, M. E., and T. R. Colvin, "Lunar Coordinates in the Regions of the Apollo Landers," Journal of Geophysical Research, Vol. 105, E8, pp. 20,277-20,280, 2000.

Hounshell, D., "The Cold War, RAND, and the Generation of Knowledge, 1946-1962," Santa Monica, Calif.: RAND, RP-729, 1998. (Reprinted from Historical Studies in the Physical and Biological Sciences, Vol. 27, No. 2, 1997). 